\title{
Acute and Late Toxicity In Breast Cancer Patient That Received Hypofractionated Adjuvant Radiotherapy after Breast- Conserving Surgery: A Case Report
}

\author{
Sinta Prastiana Dewi*, Henry Kodrat \\ Department of Radiotherapy, Faculty of Medicine, Universitas Indonesia - Dr. Cipto Mangunkusumo National General \\ Hospital, Jakarta, Indonesia
}

\section{ARTICLE INFO}

Received : 08 May 2020

Reviewed : 24 June 2020

Accepted : 19 July 2020

\section{Keywords:}

breast cancer, hypofractionated, radiotherapy, toxicity

\section{*Corresponding author:}

Sinta Prastiana Dewi

Department of Radiotherapy, Faculty of Medicine, Universitas Indonesia

- Dr. Cipto Mangunkusumo National General Hospital, Jakarta, Indonesia sintasinta@gmail.com

\author{
A BSTRACT
}

Introduction: Breast cancer is the most common female malignancy worldwide. Breastconserving surgery followed by adjuvant radiotherapy is a preferable treatment option. Hypofractionated radiotherapy is an attractive fractionation scheme because of its shorter treatment duration. This paper aims to report the short-term and long-term toxicity of hypofractionated radiotherapy in breast cancer patients at our institution.

\begin{abstract}
Case Presentation: A 58-year-old woman with right breast cancer T2N1M0 had undergone breast-conserving surgery with axilla lymph node dissection. This patient underwent adjuvant whole breast radiotherapy with a dose of $42.56 \mathrm{~Gy}$ in 16 fractions followed by tumor bed boost with a dose of $16 \mathrm{~Gy}$ in 8 fractions. After undergoing the fourth fraction of boost, she had hyperpigmentation on her radiation area (RTOG skin toxicity grade 1). At the 6-month follow-up, the hyperpigmentation still appeared. Until the 24-month follow-up, after she completed radiotherapy, there was no sign of tumor recurrence and toxicity.
\end{abstract}

Conclusion: Hypofractionated radiotherapy could be an option for breast cancer treatment that provides equivalent local control, survival, and side effects to conventional fractionation radiotherapy.

\section{INTRODUCTION}

Based on the Indonesian Ministry of Health data in 2013, the prevalence of breast cancer in Indonesia was 61,682 patients. According to GLOBOCAN 2018, the incidence of cancer in the world has increased to 18.1 million cases, with a breast cancer incidence of 2,088,849 cases $(11.6 \%)$ and a mortality rate of 626,679 cases (6.6\%) [1,2].

In breast cancer patients, adjuvant radiotherapy is aimed at preventing tumor recurrence and increasing survival. According to the Early Breast Cancer Trialists' Collaborative Group (EBCTCG), adjuvant radiotherapy after breast-conserving surgery reduces 5 -year recurrence by $13 \%$, decreases 5 -years mortality by $1 \%$, decreases 10 -year recurrence by $15.7 \%$, and decreases 10 -year mortality by $3.8 \%$ [3].

Based on many previous publications, it can be concluded that breast cancer has a low $\alpha / \beta$ ratio. The average $\alpha / \beta$ ratio of these previous studies was 2.88 Gy with a range of $2.21-4.39 \mathrm{~Gy}$. Because of it, longer fractionation does not result in significant benefits in terms of local control, and it has been proved in many randomized clinical trials. Therefore, shorter fractionation, which is called hypofractionated radiotherapy, is more interesting to be delivered to the patient because it is more convenient and the radiation treatment of acute or late toxicity is comparable with conventional fractionation. Acute toxicity is defined as the side effect occurring since the commencement of the treatment through day 90 , whereas late toxicity occurs more than 90 days after the treatment starts [4-7].

This paper aims to report the short-term and longterm toxicity of hypofractionated radiotherapy in breast cancer patients at our institution.

\section{CASE PRESENTATION}

A 58-year old woman presented with a chief complaint of a lump on her right breast. The lump felt hard, painful, and mobile. There were also 2 mobile lumps on her right armpit. The patient was diagnosed with T2N1M0 right breast cancer; then, she underwent breast-conserving surgery and axillary lymph node dissection, and, currently, she is undergoing aromatase 
inhibitor therapy. The histopathological examination result was invasive carcinoma of no special type (NST), grade 3 , free margin, positive axillary lymph nodes in 3 of 15, and no lymphovascular invasion was found.

From the immunohistochemistry examination, she was classified in Luminal B sub-groups because the estrogen and progesterone receptors were positive, Her-2 receptor was negative, and the Ki-67 index was $50 \%$. This patient received adjuvant whole breast hypofractionated radiotherapy using a $3 \mathrm{D}$ conformal radiotherapy technique with the wedge. The prescribed dose was $16 \times 2.66 \mathrm{~Gy}$ followed by $8 \times 2$ Gy boost on the tumor bed. From treatment planning results, it was found that $95 \%$ of the dose reached $97 \%$ of PTV volume and obtained $0.4 \%$ of hotspots. For the exposure to organs at risk, the contralateral breast had a mean dose of $2.4 \mathrm{~Gy}$, the ipsilateral lung $\mathrm{V} 20=26 \%$, the contralateral lung $\mathrm{V} 5=0 \%$, the heart V25 $=0 \%$, the esophagus V $45=0 \%$, and the spinal cord received a maximum dose of $1.19 \mathrm{~Gy}$. She underwent radiation treatment without any break. Figure 1.A shows the dose distribution of whole breast irradiation and Figure 1.B shows the dose distribution of boost irradiation.

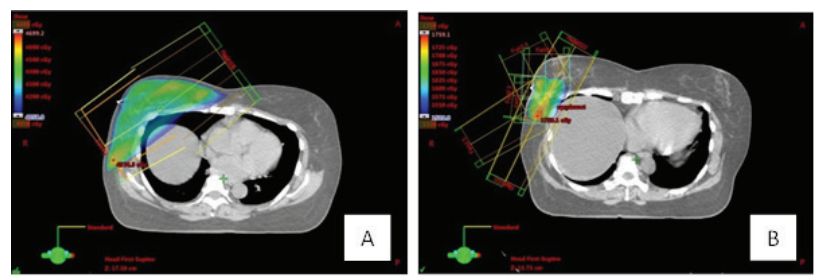

Figure 1. (A) Dose distribution of whole breast irradiation; (B) dose distribution of boost irradiation

Until the completion of the whole breast radiation with a total dose of $42.56 \mathrm{~Gy}$, there was no side effect found. The whole breast radiation was followed by a boost phase with a dose of $16 \mathrm{~Gy}$ in 8 fractions. After undergoing 4 fractions in the boost phase, we found hyperpigmentation in the radiation area (RTOG skin toxicity grade 1 ). The patient finally had completed the radiation with a good clinical response, no progressive lesions, and tolerable acute side effects on the skin.

After finished radiotherapy, the patient received 4 cycles of chemotherapy with regimens of Paclitaxel and Cisplatin followed by an aromatase inhibitor. At 6 months after the radiation finished, there was still hyperpigmentation in the radiation area without any locoregional recurrence by physical examination confirmed with ultrasonography. At 10-, 14-, and 24-month followups, we found no treatment-related toxicity, no locoregional recurrence, and no distant metastasis. Figure 2 shows the clinical picture before radiation, Figure 3.A shows the clinical picture at 10 months after radiation finished, Figure 3.B shows clinical picture at 14 months after radiation finished, and Figure 3.C shows clinical picture at 24 months after radiation finished.
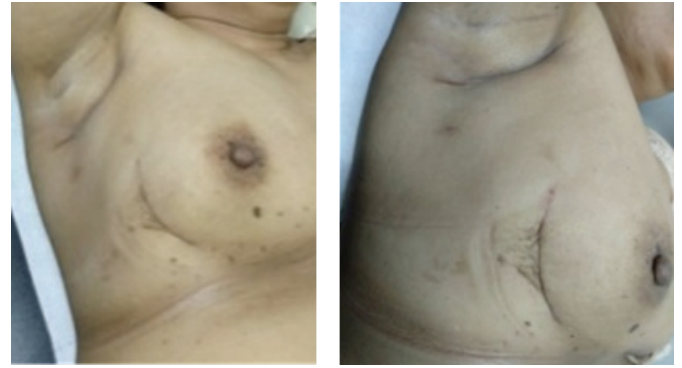

Figure 2. Clinical picture before radiation
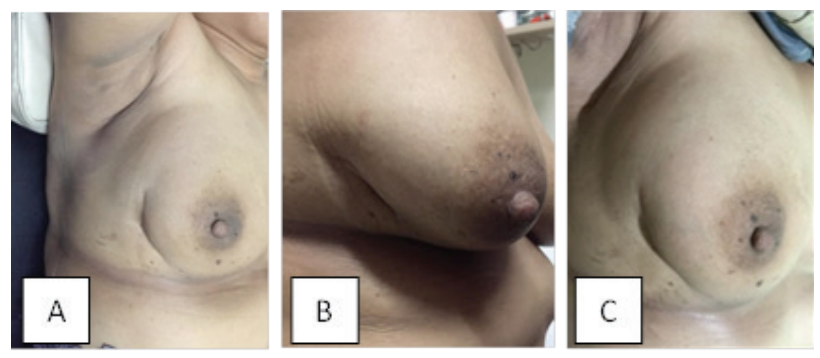

Figure 3. (A) Clinical picture at 10 months after radiation finished; (B) 14 months after radiation finished; (C) 24 months after radiation finished

\section{DISCUSSION}

In this case, the patient underwent breast-conserving surgery followed by adjuvant radiotherapy. Radiotherapy was delivered in a hypofractionated scheme to shorten the radiation treatment period, so she could undergo adjuvant chemotherapy as soon as possible. Less fraction radiotherapy could also save costs incurred by both the patient and the government. According to ASTRO guidelines in 2018, hypofractionated radiotherapy could be given without considering the patient's age and stage without additional regional lymph node radiation, in patients with or without chemotherapy, and it is expected that the volume of breast tissue that receives $105 \%$ prescription dose should be minimized [6].

The patient was given the whole breast radiation with a dose of $16 \times 2.66$ Gy followed by a boost dose of $8 \times$ $2 \mathrm{~Gy}$ in the tumor bed, with a total dose equivalent to EQD2 $59.2 \mathrm{~Gy}$. This EQD2 value was similar to conventional fractions with a scheme of $25 \times 2$ Gy followed by $5 \times 2$ $\mathrm{Gy}$ of boost. The radiation was delivered with a $6 \mathrm{MV}$ photon energy using a linear accelerator machine. In this patient, the boost dose was given in accordance with the National Comprehensive Cancer Network (NCCN) which provides a boost dose of $10-16 \mathrm{~Gy}$ in $4-8$ fractions [8]. Meanwhile, in the studies of START A and B, boost in tumor bed was not always delivered. Boost was recommended at a dose of $10 \mathrm{~Gy}$ in 5 fractions. Tumor bed boost was performed in $61 \%$ of patients at START A and $43 \%$ at START B, whereas in the Whelan study, tumor bed boost was not allowed [3,9-11]. 
The aim of giving a boost, in this case, was to reduce the risk of local recurrence in the patient. In accordance with ASTRO 2018 guidelines, patients aged 51-70 years with high-grade pathology results are strongly recommended for a boost. In a study conducted by Bartelink et al. [12], it was found that the number of local ipsilateral breast recurrence in patients without a boost was $13 \%$ while in patients who received a boost was $9 \%$ (HR 0.65, 99\% Cl 0.52-0.81, $P<.0001$ ). On the other hand, there was no significant 20-year survival difference between the patients who received and did not receive a radiation boost. In the European Organization for Research and Treatment (EORTC) study 22881-10882, there was also a higher cumulative incidence of local recurrence in patients without boost compared with those who received a boost with a 10 -year recurrence incidence rate of $10.2 \%$ compared to $6.2 \%(P<.0001)[6,12,13]$.

Besides those doses, according to the Forum for Nuclear Cooperation in Asia (FNCA) study, the boost could be given in a scheme of $3 \times 2.7 \mathrm{~Gy}$ which follows the whole breast irradiation dose of $16 \times 2.7 \mathrm{~Gy}$. The total dose of EQD2 is 57.29 Gy which is not much different from the total dose of EQD2 in the conventional fraction. In the FNCA study period of February 2013 until October 2017, there were 235 cases of radiotherapy with 163 patients receiving radiation boost to tumor beds. From the observation, they found acute dermatitis grade $\geq 2$ in 26 patients. For advanced toxicity, grade- 2 pulmonary toxicity was obtained in 1 patient, grade- 2 skin toxicity in 1 patient, and grade- 2 subcutaneous toxicity in 1 patient. During that observation follow-up, they also found 1 locoregional recurrence, 3 distant metastases, and 2 cases of death related to breast cancer [14].

In this case illustration, there were grade- 1 skin side effects that appeared after the 4th fraction of the boost phase. The side effects appeared as hyperpigmentation in the radiation area, without wet desquamation or any pain. These side effects continued until the patient was followed up at 6 months after radiation. After that, up to 24-month follow-up, after radiotherapy was completed, we found no treatment-related toxicity in the radiation area such as breast shrinkage, breast hardness, and telangiectasia. For other organs at risk such as the lungs, heart, contralateral breast, esophagus, and spinal cord, acute and late toxicity has not been reported until recently. This clinical finding was consistent with the result of treatment planning, where there were no organs at risk that received doses exceeding the constraints.

From the hypofractionated radiotherapy studies, $\mathrm{RMH} /$ GOC, START A, START B, and Whelan, we know that patients who underwent hypofractionated radiotherapy had a lower hazard ratio of skin toxicity than those who underwent conventional fraction. At this time, there is no evidence that patients who underwent hypofractionated radiotherapy have more severe side effects than those who had conventional fractions [5]. Table 1 shows the recurrence and side effects in conventional and hypofractionated radiotherapy.

A similar result was reported by Osako et al. [15] whose study compared the incidence of dermatitis and pneumonitis in breast radiation after breast-conserving surgery and adjuvant radiotherapy with conventional fractions and with the hypofractionated scheme. Patients were evaluated using Common Terminology Criteria for Adverse Events (CTCAE) version 3. The results of the grade-2 and -3 dermatitis on hypofractionated radiotherapy were $13 \%$ lower than in the conventional fraction $(P=.016)$ and grade- 2 pneumonitis was $1 \%$ in patients with conventional radiation, but there was no pneumonitis in hypofractionated radiotherapy.

Table 1. Recurrence and side effects in conventional and hypofractionated radiotherapy.

\begin{tabular}{|c|c|c|c|c|c|c|c|}
\hline Study & Design & $\begin{array}{l}\text { Sample } \\
\text { (n) }\end{array}$ & $\begin{array}{l}\text { Dose }(G y) / \\
\text { fraction }\end{array}$ & $\begin{array}{l}\text { Locoregiona } \\
\text { 5/10 year }\end{array}$ & $\begin{array}{l}\text { recurrence } \\
\text { (\%) }\end{array}$ & $\begin{array}{l}5 \text { year skin toxicity } \\
\text { (\% or HR) }\end{array}$ & Other acute toxicity (\%) \\
\hline $\begin{array}{l}\text { RMH/ } \\
\text { GOC } \\
{[16]}\end{array}$ & $\mathrm{RCT}$ & 1410 & $\begin{array}{l}50 / 25 \\
42.9 / 13 \\
39 / 13\end{array}$ & 10 year & $\begin{array}{l}12.1 \\
14.8 \\
9.6\end{array}$ & $\begin{array}{l}12.0 \\
13.0 \\
5.6\end{array}$ & $\mathrm{~N} / \mathrm{A}$ \\
\hline $\begin{array}{l}\text { START A } \\
\text { [9] }\end{array}$ & $\mathrm{RCT}$ & 2236 & $\begin{array}{l}50 / 25 \\
41.6 / 13 \\
39 / 13\end{array}$ & 5 year & $\begin{array}{l}3.6 \\
5.2 \\
3.5\end{array}$ & $\begin{array}{l}1.0 \\
0.83 \\
0.63\end{array}$ & $\begin{array}{l}\text { Breast shrinkage }(20.4 / 23.4 / 22.3) \\
\text { Breast stiffness }(42.6 / 44.6 / 34.9) \\
\text { Breast edema }(15.2 / 12.1 / 12.0)\end{array}$ \\
\hline $\begin{array}{l}\text { START B } \\
{[10]}\end{array}$ & $\mathrm{RCT}$ & 2215 & $\begin{array}{l}50 / 25 \\
40 / 15\end{array}$ & 5 year & $\begin{array}{l}3.3 \\
2.2\end{array}$ & $\begin{array}{l}1.0 \\
0.76\end{array}$ & $\begin{array}{l}\text { Breast shrinkage }(24.4 / 23.2) \\
\text { Breast stiffness }(42.3 / 38.2) \\
\text { Breast edema }(12.4 / 10.5)\end{array}$ \\
\hline $\begin{array}{l}\text { Whelan } \\
\text { [11] }\end{array}$ & $\mathrm{RCT}$ & 1234 & $\begin{array}{l}50 / 25 \\
42.5 / 16\end{array}$ & $5 / 10$ year & $\begin{array}{l}3.2 / 6.7 \\
2.8 / 6.2\end{array}$ & $\begin{array}{l}3.3 \\
3.2\end{array}$ & $\mathrm{~N} / \mathrm{A}$ \\
\hline $\begin{array}{l}\text { FNCA } \\
{[14]}\end{array}$ & Prospective & 406 & $\begin{array}{l}43.2 / 16 \\
\pm \text { boost } \\
8.1 / 3\end{array}$ & 5 year & 1.4 & 6 & $\mathrm{~N} / \mathrm{A}$ \\
\hline
\end{tabular}

RMH/GOC: Royal Marsden Hospital / Gloucestershire Oncology CenterSTART A: Standardization of Breast Therapy A

START B: Standardization of Breast Therapy B

FNCA: Forum for Nuclear Cooperation in Asia

RCT: Randomized Control Tria 
In the START A study, after a median follow-up of 5.1 years, 5 -year locoregional relapses was $3.6 \%$ in the 50 Gy group (95\% Cl $2.2-5.1$ ), 3.5\% in 41.6 Gy group (95\% Cl 2.1 - 4.3), and 5.2\% in 39 Gy (95\% Cl $3.5-6.9)$. Photographs and patient self-assessments showed a lower rate of late adverse events in the group of 39 Gy compared to $50 \mathrm{~Gy}$ with a hazard ratio of 0.69 . In the START B study, after a 6-year follow-up median, the 5-year recurrence rate in the 40 Gy group was 2.2 $\%(95 \% \mathrm{Cl} 1.3-3.1)$ and $3.3 \%(95 \% \mathrm{Cl} 2.2$ to 4.5$)$ in the 50 Gy group. From both studies, 5-year locoregional recurrence rates were lower in the hypofractionated radiation group than in the conventional fraction group. In the study by Whelan et al. [11], after 10 years of follow-up, patients who underwent conventional radiation had $6.7 \%$ local recurrence and those who underwent hypofractionated radiation had $6.2 \%$ local recurrence. In the $\mathrm{RMH} / \mathrm{GOC}$ study, after a median follow-up of 9.7 years, the 10 -year recurrence risk rate was $12.1 \%$ in the 50 Gy group, $14.8 \%$ in 39 Gy group, and $9.6 \%$ in 42.9 Gy group [9-11,16].

There are several predictors of breast radiation toxicity. Parekh et al. [17] found a relationship between the incidence of breast irradiation acute skin toxicity related to the type of surgery, the number of fractions, Body Mass Index (BMI), regional lymph node radiation, and chemotherapy. In post-radiation breast cancer patients, wet desquamation occurred in $24 \%$ post-mastectomy patients and $8.7 \%$ post-BCS patients. When the fractionation scheme is compared, wet desquamation occurred in $10.9 \%$ and $1.8 \%$ of patients undergoing conventional fractionation and hypofractionation, respectively. The study showed that higher BMI increases skin toxicity incidence. Regional lymph node radiation and chemotherapy are also predictors of breast toxicity. In this case, the patient had BMI of 29.29 $\mathrm{kg} / \mathrm{m} 2$, classified as grade-l obesity, which could be a predictor of acute toxicity.

The radiation technique also affects the occurrence of toxicity to the skin. Modern radiation techniques such as intensity-modulated radiotherapy (IMRT), either inverse or forward planning (field-in-field/FIF), can reduce hotspots on the skin with better homogeneity compared to simple radiation with a wedge. With the reduction of hotspots, toxicity is also expected to decrease. IMRT is also beneficial to reduce the incidence of late side effects on the skin, such as induration and telangiectasia [18].

Some techniques could be the options in breast radiation, such as 2D, 3D, and IMRT. The radiation technique performed on this patient was $3 \mathrm{D}$ conformal radiotherapy with a wedge. Wedge was used to homogenizing the dose distribution in PTV and to avoid hotspot dose. If there were lots of hotspots and the homogeneity was not achieved by a wedge, the use of the field-in-field technique and IMRT could be considered. From a study by Donovan et al. [19] in 2002, in a standard technique with a wedge, PTV that received $>105 \%$ of the dose was $11.7 \%$, whereas, in the IMRT technique, the PTV who received $>105 \%$ of the dose was $1 \%(P<.001)$. In a study by Donovan et al. [20] in 2007, they compared changes in breast appearance in groups that underwent 2D and 3D IMRT radiation techniques. At the 5-year evaluation, the 2D group had breast appearance changes 1.7 times more than that of the 3D IMRT group $(P=.008,95 \% \mathrm{Cl} 1.2-$ 2.5). Fewer patients experience breast induration in inframammary folds, pectoral folds, and boost area.

In breast cancer patients who underwent breastconserving surgery, radiation boost can be delivered sequentially or concomitantly. In a study by De Rose et al. [21], they observed skin side effects after hypofractionated radiotherapy with simultaneous integrated boost (SIB) after breast-conserving surgery with or without adjuvant chemotherapy and immunotherapy. In the group that received radiotherapy only, acute skin toxicity grades 1,2 , and 3 were $48.5 \%$, $14.1 \%$, and $0.2 \%$, respectively. Meanwhile, in the combined chemotherapy and immunotherapy group, the same toxicity was $51.1 \%, 9.7 \%$, and $0 \%$. At 2 years of follow-up in the combined chemotherapy and immunotherapy group, the grade- 1 and grade- 2 skin toxicity was $13.5 \%$ and $0 \%$, respectively. By this study, we know that hypofractionated whole-breast radiotherapy with SIB can be a safe option for delivering a boost in patients with adjuvant systemic therapy.

\section{CONCLUSIONS}

Hypofractionated radiotherapy can be a choice in breast cancer treatment that promises equivalent local tumor control, survival, and side effects equivalent to conventional fraction radiotherapy. By choosing hypofractionated radiotherapy, we can save time and cost, shorten treatment duration, increase patients' comfort, and increase treatment capacity. There have been many studies of hypofractionated radiotherapy that have focused on the efficacy of success and side effects. We hope that we can conduct a prospective study to assess treatment response and toxicity in our population, so hypofractionated radiotherapy can be more widely applied to various institutions especially during Covid-19 pandemics.

\section{DECLARATIONS}

\section{Competing of Interest}

The author(s) declare no competing interest in this paper.

\section{Acknowledgment}

We thank our patient for allowing us to share her details. 


\section{REFERENCES}

1. Kementrian Kesehatan RI. Buletin Jendela Data \& Informasi Kesehatan: Situasi penyakit kanker [Internet]. 2015 [cited 2020 Jun 29]. Available from: https:// pusdatin.kemkes.go.id/download.php?file=download/ pusdatin/buletin/Buletin-SIK-2016.pdf.

2. International Agency for Research on Cancer. Cancer Today [Internet]. 2018 [cited 2020 Jun 29]. Available from: https://gco.iarc.fr/today/online-analysispie? $\mathrm{v}=2018 \&$ mode $=$ cancer\&mode_population=continen ts\&population $=900 \&$ populations $=900 \&$ key $=$ total $\&$ sex $=0$ \&cancer $=39$ \&type $=0$ \&statistic $=5$ \&prevalence $=0$ \&populat ion_group $=0$ \&ages_group $\% 5 B \% 5 D=0$ \&ages_ group $\% 5 B \% 5 D=17 \& n b \_i$ tems $=7 \&$ group_ cancer=1\&include_nmsc=1\&include_nmsc_other=1\&half_ pie=0\&donut=0\&population_group_globocan_id=

3. Darby S, McGale P, Correa C, et al. Effect of radiotherapy after breast-conserving surgery on 10-year recurrence and 15-year breast cancer death: Meta-analysis of individual patient data for 10801 women in 17 randomised trials. Lancet. 2011;378(9804):1707-16.

4. Qi XS, White J, Li XA. Is $\alpha / \beta$ for breast cancer really low? Radiother Oncol. 2011;100(2):282-8.

5. Holloway CL, Panet-Raymond V, Olivotto I. Hypofractionation should be the new "standard" for radiation therapy after breast conserving surgery. Breast. 2010;19(3):163-7.

6. Smith BD, Bellon JR, Blitzblau R, et al. Radiation therapy for the whole breast : Executive summary of an American Society for Radiation Oncology (ASTRO) evidence-based guideline. Pract Radiat Oncol. 2018;8(3):145-52.

7. Cox JD, Stetz JA, Pajak TF. Toxicity criteria of the Radiation Therapy Oncology Group (RTOG) and the European organization for research and treatment of cancer (EORTC). Int J Radiat Oncol Biol Phys. 1995;31(5):1341-6.

8. Stuckey A. Breast Cancer. Clin Obstet Gynecol. 2011;54(1):96-102.

9. Agrawal RK, Aird EGA, Barrett JM, et al. A The UK Standardisation of Breast Radiotherapy (START) Trial A of radiotherapy hypofractionation for treatment of early breast cancer: a randomised trial. Lancet. 2008;9:331-41.

10. Agrawal RK, Aird EGA, Barrett JM, et al. The UK Standardisation of Breast Radiotherapy (START) Trial $B$ of radiotherapy hypofractionation for treatment of early breast cancer: a randomised trial. Lancet. 2008;371(9618):1098-107.
11. Whelan TJ, Pignol J-P, Levine MN, et al. Long-term results of hypofractionated radiation therapy for breast cancer. N Engl J Med. 2010;362(6):513-20.

12. Bartelink $H$, Maingon $P$, Poortmans $P$, et al. Wholebreast irradiation with or without a boost for patients treated with breast-conserving surgery for early breast cancer: 20-year follow-up of a randomised phase 3 trial. Lancet Oncol. 2015;16(1):47-56.

13. Bartelink H, Horiot JC, Poortmans PM, et al. Impact of a higher radiation dose on local control and survival in breast-conserving therapy of early breast cancer: 10-Year results of the randomized boost versus no boost EORTC 22881-10882 trial. J Clin Oncol. 2007;25(22):3259-65.

14. Karasawa K, Banu AP, Tasbolat A, et al. A prospective international study on safety and efficacy of hypofractionated radiation therapy for post-operative breast cancer patients in asian countries. Int J Radiat Oncol. 2018;102(3):e577.

15. Osako T, Oguchi M, Kumada $M$, et al. Acute radiation dermatitis and pneumonitis in japanese breast cancer patients with whole breast hypofractionated radiotherapy compared to conventional radiotherapy. Jpn J Clin Oncol. 2008;38(5):334-8.

16. Owen JR, Ashton A, Bliss JM, et al. Effect of radiotherapy fraction size on tumour control in patients with early-stage breast cancer after local tumour excision: long-term results of a randomised trial. Lancet Oncol. 2006;7(6):467-71.

17. Parekh A, Dholakia AD, Zabranksy DJ, et al. Predictors of radiation-induced acute skin toxicity in breast cancer at a single institution: Role of fractionation and treatment volume. Adv Radiat Oncol. 2018;3(1):8-15.

18. Bray FN, Simmons BJ, Wolfson AH, Nouri K. Acute and chronic cutaneous reactions to ionizing radiation therapy. Dermatol Ther (Heidelb). 2016;6(2):185-206.

19. Donovan EM, Bleackley NJ, Evans PM, Reise SF. Doseposition and dose-volume histogram analysis of standard wedged and intensity modulated treatments in breast radiotherapy. Br J Radiol. 2002;75:967-73.

20. Donovan E, Bleakley N, Denholm E, Evans P, Gothard L, Hanson J, et al. Randomised trial of standard 2D radiotherapy (RT) versus intensity modulated radiotherapy ( IMRT ) in patients prescribed breast radiotherapy. Radiother Oncol. 2007;82:254-64.

21. Rose F De, Fogliata A, Franceschini D, Iftode C, Navarria $\mathrm{P}$, Comito $\mathrm{T}$, et al. Hypofractionation with simultaneous boost in breast cancer patients receiving adjuvant chemotherapy: A prospective evaluation of a case series and review of the literature. The Breast. 2018;42:31-7. 